\title{
Koori voices: self-harm, suicide attempts, arrests and substance use among Aboriginal and Torres Strait Islander adolescents following residential treatment
}

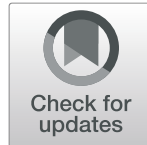

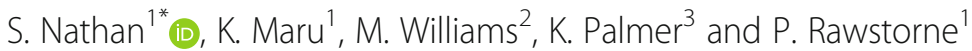

\begin{abstract}
Background: Complex interacting social, economic and historical factors influence the availability and uptake of alcohol and drugs, including among Indigenous communities. Self-harm and suicide as well as homelessness and incarceration, can both precede and result from drug and alcohol use. Rates of self-harm, suicide and incarceration among Aboriginal and Torres Strait Islander people in Australia are among the highest in the world and drug and alcohol treatment programs need to address these underlying complexities. This study examines whether an 'holistic' residential drug and alcohol treatment program for adolescents, with over 30\% of clients identifying as Aboriginal and Torres Strait Islander, can improve outcomes post-discharge, including reducing self-harm, suicide attempts, arrests and alcohol and drug use. The program addresses substance use, mental health, employment, accommodation, social/community and family life. Program admission and 3 months' post-discharge data from 2007 to 2016 were analysed.
\end{abstract}

Results: From 2007 to 2016, 619 Aboriginal and Torres Strait Islander young people were admitted to the program; 247 stayed in the program for 30 days or more; 89 were successfully followed up three months post-discharge to determine whether there was a significant improvement from baseline using the McNemar's Test and the Wilcoxon Signed Ranks Test. On admission, 18 people (20\%) of the study population reported attempting suicide in the last 3 months and 23 people (30\%) reported self-harm. Most had been engaged in the criminal justice system, with 67 people (75\%) having been to court and 62 people (70\%) arrested one or more times in the past 3 months, with 35 people (41\%) in unstable housing, reporting having lived in three or more places in the previous 6 months. At 3 months post-treatment, all $(n=18)$ who reported suicide attempts in the 3 months prior to admission reported no attempts in the prior 3 months at follow-up. There was also a significant reduction in self-harm with 23 young people out of the 27 who reported self-harm at baseline not reporting self-harm at follow up (85\%) and in the proportion of adolescents who reported using cannabis, amphetamines and alcohol, as well as a reduction in the proportion who reported being arrested.

Conclusions: The findings provide support for an 'holistic' residential treatment program as an approach to improve health and related outcomes for Aboriginal and Torres Strait Islander young people. In addition to a focus on multiple aspects of a young person's life in treatment, culturally relevant modes of treatment and support should be a future focus to further strengthen programs when Aboriginal and Torres Strait Islander young people are over-represented in the client group.

Keywords: Aboriginal and Torres Strait islander, Indigenous, Adolescents, Young people, Drugs, Alcohol, Residential treatment, Suicide, Self-harm, Outcomes

\footnotetext{
* Correspondence: s.nathan@unsw.edu.au

'School of Public Health and Community Medicine, UNSW, Sydney, Australia

Full list of author information is available at the end of the article
}

(c) The Author(s). 2020 Open Access This article is distributed under the terms of the Creative Commons Attribution 4.0 International License (http://creativecommons.org/licenses/by/4.0/), which permits unrestricted use, distribution, and reproduction in any medium, provided you give appropriate credit to the original author(s) and the source, provide a link to the Creative Commons license, and indicate if changes were made. 


\section{Background}

Complex interacting social, economic and historical factors influence the availability, uptake and use of alcohol and drugs as well as the strategies used to reduce associated risks and harms. Factors, such as homelessness, lower socioeconomic status, incarceration and violence, can both precede and result from drug and alcohol use (Fox, Oliver, \& Ellis, 2013; Whitesell, Bachand, Peel, \& Brown, 2013). In Australia, a harm minimisation framework underpins many of the approaches to drug and alcohol use (Australian Department of Health, 2011), however, there remains high levels of alcohol consumption in the general community (AIHW, 2014), and high rates of illicit drug use compared to many other countries (AIHW, 2011a).

Within the broader Australian context, the health and wellbeing of Aboriginal and Torres Strait Islander people is worsening with the national government unable to meet its own targets to reduce health and social inequity (CoA, 2017). Aboriginal and Torres Strait Islander peoples constitute $2.8 \%$ of the total population (ABS, 2016; Madden, Tickle, Jackson Pulver, \& Ring, 2012). For 60,000 years before colonisation in 1788, the 300-plus inter-dependent nation groups flourished with systems for nutrition, law, relationships, identity and survival. After the British proclaimed ownership (Kidd, 1997; Perkins, 2010), introduced infectious diseases and alcohol, restriction from traditional foods, massacres, poisonings and lack of healthcare, resulted in innumerable deaths (Attwood, 2005; Elder, 2003). It was not until 1967 that Aboriginal and Torres Strait Islander people were considered citizens. Despite never ceding sovereignty Aboriginal and Torres Strait Islander people continue to suffer profound injustices in Australian society (Burgess \& Johnstone, 2007; Strelein, 2009).

Over-representation in correctional centres (ABS, 2017) and high rates of youth detention (AIHW, 2016) reinforce deep wounds created by deliberate removal of children from families under past policies. These 'Stolen Generations' have significantly higher alcohol and drug use, post-traumatic stress disorder and other illnesses with inadequate resources for therapeutic care than the general Australian population (Human Rights and Equal Opportunities Commission, 1997; Phillips, 2007). Emerging evidence now shows a biological as well as social effect of trauma, with trauma effects extending intergenerationally to individuals and their families (Atkinson, 2002; Atkinson, 2009). International research shows higher levels of trauma, mental illness and suicide among Indigenous peoples removed from family and has been associated with poorer health among those in Canada, New Zealand and Australia (Elias et al., 2012; King, Smith, \& Gracey, 2009; Waldram, Herring, \& Young, 2006). The loss of connection to cultural life, trauma, racism and social exclusion contribute to poorer health including harmful alcohol and drug consumption (Dixson et al., 2018; Waldram, Herring \& Young, 2006). The health status of Indigenous populations worldwide are poorer than non-Indigenous populations with similar alcohol and drug use patterns (Pulver et al., 2010). A recent systematic review examined suicide rates among Indigenous peoples in 30 countries and territories (Pollock, Naicker, Loro, Mulay, \& Colman, 2018). The majority of the studies sourced focused on populations in high-income nations including Australia. Results showed that suicide rates are elevated above non-Indigenous rates in many Indigenous populations worldwide with the highest at 50.4 per 100 , 000 among Aboriginal and Torres Strait Islanders in the Northern Territory of Australia.

In Australia, national data shows Aboriginal students have lower retention rates in school in both years 11 and 12 (the final years of schooling) with the year 12 retention rate being $55.1 \%$ compared to other students (82.9\%) (AIHW, 2015). Employment, a protective factor against harmful drug and alcohol use (Spooner \& Hetherington, 2005), is lower among Aboriginal people compared to other Australians (ABS, 2014), and lower incomes resulting from lower levels of educational attainment and employment are associated with higher rates of morbidity and mortality, including from drug and alcohol use (AIHW, 2015; Galea, Nandi, \& Vlahov, 2004).

National health frameworks (Australian Department of Health, 2013; CoA, 2017), service delivery reviews (Haswell, Blignault, Fitzpatrick, \& Jackson Pulver, 2013) and other research (Bennett, Green, Gilbert, \& Bessarab, 2013; Gray, Saggers, Atkinson, \& Wilkes, 2008; Laliberté, Haswell-Elkins, \& Reilly, 2009; Nagel, Robinson, Condon, \& Trauer, 2009; Phillips, 2003) highlight the need for Aboriginal and Torres Strait Islander-led holistic care that address multiple individual as well as family needs, strengthens cultural identity, and develops the capacity of the workforce and systems to address inequity. 'Mainstream' drug and alcohol treatment services are generally under-accessed by Aboriginal and Torres Strait Islander people (AIHW, 2011b) and evidence for how well they deliver 'best practice' for Aboriginal and Torres Strait Islander people is consequently missing from the peerreviewed literature (Gray et al., 2014; Rowan et al., 2014; Taylor, Thompson, \& Davis, 2010).

Internationally there have been very few robust outcome studies focussed on residential treatment outcomes for young people with drug and alcohol issues (Nathan et al., 2016; Nathan, Bethmont, Rawstorne, Ferry, \& Hayen, 2016). Importantly, length of stay and program completion in residential programs has been found to be associated with improved outcomes in the short term with both adults and young people (Darke, Campbell, \& Popple, 2012; Edelen, Slaughter, McCaffrey, 
Becker, \& Morral, 2010; Galaif, Hser, Grella, \& Joshi, 2001; Mills, Pepler, \& Cribbie, 2013; Orlando, Chan, \& Morral, 2003). However, the lack of comparison groups in many studies has been problematic for attributing causality (Muck et al., 2001; Tripodi, 2009; Williams \& Chang, 2000). These challenges in study design are compounded in research with Aboriginal and Torres Strait islander people given their small numbers as a proportion of the general population (AIHW, 2019). This translates to small numbers accessing and being represented in the treatment population even though Aboriginal and Torres Strait islander people are over-represented in the population receiving drug and alcohol treatment with around 1 in 6 (16\%) clients identifying as Aboriginal or Torres Strait Islander in Australian treatment data (AIHW, 2019).

Study designs with a comparison group and randomisation remain ethically and logistically challenging in drug and alcohol studies, especially with young people and furthermore with those who identify as Aboriginal or Torres Strait Islander (Muck et al., 2001; Tripodi, 2009; Williams \& Chang, 2000). There has consequently been very few RCT studies of residential (including Therapeutic Community) treatment programs in the mental health field more broadly (Pearce et al., 2017), and none identified with young people in the drug and alcohol treatment literature. There are also no studies we have been able to identify internationally with a focus on Indigenous young people and their experience and outcomes following residential drug and alcohol treatment.

Studies of adolescents in residential drug and alcohol treatment centres in the United States have shown significant reductions in drug and alcohol use and crime, and improvements in social and psychological well-being post treatment, though findings are mixed and study designs variable (Battjes et al., 2004; Edelen et al., 2010; Hser et al., 2001; Muck et al., 2001; Williams \& Chang, 2000). There have been few treatment outcome studies identified in Australia focussed on adolescents (Spooner, Mattick, \& Noffs, 2001) and none specifically focussed on Aboriginal young people. With over half of the Aboriginal and Torres Strait Islander population being under 25 years of age (ABS, 2016), the need to identify effective treatment approaches for young Aboriginal and Torres Strait Islander people with problematic drug and alcohol use is urgent.

The current study focusses on a residential treatment program that aims to address young people's individual needs in treatment and which includes program elements to connect Aboriginal young people to culture and community. This paper examines whether Aboriginal and Torres Strait Islander young people who stay in the program long enough to receive a potential benefit show improvement on key measures 3 months' postdischarge from this program.

\section{The program}

The residential treatment program is a therapeutic community (TC) approach modified for young people (aged 13-18 years) who have problems with drugs and alcohol (see Participants section). A TC approach utilises the livein community as a treatment tool and catalyst for change, with emphasis on treating the whole person (De Leon, 2000). The program, which has a stay of up to 3 months, aims to create a supportive drug-free environment for young people (13-18 years old), to encourage them to develop skills to manage their lives and reduce their drug and alcohol use (Nathan, Rawstorne, et al., 2016).

The program takes a harm minimisation approach, not expecting all individuals to be abstinent post-treatment (AIHW, 2014). The goal is to ensure individuals establish a positive basis for life outside the programme, which may include improvements in mental health, stability in employment, accommodation, social and family life (Nathan, Bethmont, Rawstorne, Ferry \& Hayen, 2016). The program uses individual and group therapy, vocational education and other TC elements to effect change (Nathan, Rawstorne, et al., 2016). This program also has a continuing care service post-discharge, for up to 3 years, which aims to support young people back in the community. The continuing care aims to help them maintain positive changes in drug and alcohol use, and mental health, and to find stable housing, employment and build positive connections and relationships in the community.

\section{Program participants}

Young people are referred to the program from the juvenile justice system, and community (including self, family or case worker) with high levels of trauma, poor mental health, history or arrests and unstable housing (Dixson et al. 2018, Nathan, Bethmont, Rawstorne, Ferry \& Hayen, 2016). Those admitted meet the Diagnostic and Statistical Manual of Mental Disorders, 4th Edition (DSM IV) criteria for substance abuse or dependence (American Psychiatric Association, 2013). DSM IV criteria rather than DSMV are used by the program to ensure consistency and continuity in the eligibility criteria and in data collection. Furthermore, while the DSM V provides clear criteria for 'substance use disorder' and severity indicators, it does not have the same distinction as the DSM IV between 'substance abuse' and 'substance dependence', which has been argued to not capture broader social dimensions of problematic drug use, particularly in adolescent populations (Falck, Nahhas, Li, \& Carlson, 2012).

Young people are not eligible for admission to the program if they are not aged between 13 and 18 years, do not meet the DSMIV criteria for substance dependence or have a criminal justice history that means they are unlikely to be suitable for a residential treatment program with other young people. For example, a history of 
sexual assault convictions or multiple convictions for arson. Young people are also sometimes refused bail by the criminal justice system and are not able to be admitted to the program. Those who do not meet the DSMIV criteria for substance dependence are referred for outpatient counselling.

\section{Method}

This analysis of Aboriginal and Torres Strait Islander young people aged 13-18 years admitted to the TC from 2007 to 2016 investigates personal characteristics, drug use patterns, and experiences such as arrests, self-harm and suicide attempts before admission to the program and 3 months' post-discharge. Only those who stayed 30 days or more in the program were followed up at three-months post-discharge as the program routinely only follows up young people with a minimum stay of 30 days. This 30 day stay is considered by the program staff and management as a minimum time in treatment that is required to have any demonstrable impact. Additionally, this follow up rule enables the program to maximise the value of staff resources required for follow up balanced against expectations of client changes post treatment.

\section{Research questions}

Improvements in the same domains as other published studies in the US may be expected, but given the lack of research among Aboriginal young people no hypotheses were posed.

Research questions:

1. Is there a significant reduction in drug and alcohol use 3 months' post-discharge from the program compared to baseline?

2. Is there a significant improvement in psychological well-being including a reduction in self-harm and suicide attempts 3 months' post-discharge from the program compared to baseline?

3. Is there a significant improvement in family and social functioning 3 months' post-discharge from the program compared to baseline?

4. Is there a significant reduction in arrests for Aboriginal and/or Torres Strait Islander young people 3 months' post-discharge from the program compared to baseline?

5. Is there a significant improvement in engagement in study or employment for Aboriginal and/or Torres Strait Islander young people 3 months' postdischarge from the program compared to baseline?

\section{Ethics and governance}

This study and the publication have been approved by the Aboriginal Health and Medical Research Council (AHMRC) Ethics Committee of NSW (Ref: 1144/15).
Approval was also received from the Human Research Ethics Committee (HREC) of the University of New South Wales (UNSW) (Ref: HC13014). An Aboriginal Advisory Committee (AAC) guided the study, with representatives of Aboriginal organisations, researchers, staff and young people who have completed the program. All young people consented to their data being used in research.

\section{Study design and data collection}

The study design was a pre/post treatment program follow up study. Data included baseline and three-month follow-up repeated measures for young Aboriginal and Torres Strait Islander people admitted to the program from beginning 2007 to end 2016 who stayed 30 days or more; this is the timeframe used to determine eligibility for 3 months' post-discharge follow-up by the program. Data were collected over the telephone by program staff using an electronic database to enter responses to the assessment instrument.

\section{Measures}

Drug use measures included current use (yes/no) of the three most common drugs: tobacco, cannabis and amphetamine type stimulants (ATS) (Nathan, Bethmont, Rawstorne, Ferry \& Hayen, 2016), number of days drinking alcohol in the past month and number of drugs used. Other items included engagement in study or work, arrests in the previous 3 months, self-harm and suicide attempts in the last 3 months and time spent with family and with friends who do not use drugs. These measures have been described in further detail in a previous publication (Dixson et al., 2018). Nonsuicidal self-injury (NSSI) is defined as the deliberate, selfinflicted destruction of body tissue without suicidal intent which is also commonly referred to as self-harm (Zetterqvist, 2015). One dependence and two functioning scales were also a focus of analysis, described in more detail in Table 1. While these scores were developed for an adult population and not validated among Aboriginal and Torres Strait Islander populations, the program has used them for several years, with practicewisdom suggesting they have been useful in measuring change.

\section{Data analysis}

To measure statistical significance of dichotomous variables prior to admission and 3 months post-discharge, McNemar's Test was used with $p<0.05$ as the cut-off value for significance. Analyses using McNemar's Test applied to: proportion of participants using ATS, cannabis and tobacco in the preceding month before admission compared with the month before follow-month; spending time with family and friends; self-harm and attempted suicide; engagement in work or study; and 
Table 1 Scales included in the analysis

\begin{tabular}{|c|c|c|}
\hline Scales & Constructs measured & Description of measurement scale \\
\hline Severity of Dependence Scale (SDS) & $\begin{array}{l}\text { Five-item questionnaire measuring psychological } \\
\text { dependence on different illicit drugs. A score } \\
\text { from zero to three is used for each item, and } \\
\text { then totalled (Lawrinson, Copeland, \& Indig, 2005). } \\
\text { If a cut-off score greater than three is measured, } \\
\text { this is an indication for problematic alcohol use } \\
\text { (Lawrinson, Copeland, Gerber, \& Gilmour, 2007). } \\
\text { If a cut-off score greater than four is measured, } \\
\text { this is an indication for problematic drug use } \\
\text { (Martin, Copeland, Gates, \& Gilmour, 2006; } \\
\text { Topp \& Mattick, 1997). }\end{array}$ & $\begin{array}{l}0=\text { never/almost never } \\
1=\text { sometimes } \\
2=\text { often } \\
3=\text { always/nearly always } \\
\text { The scores are added together. The higher } \\
\text { the score, the more problematic drug use. }\end{array}$ \\
\hline General Functioning Scale & $\begin{array}{l}\text { A sub-scale of the Family Assessment Device } \\
\text { (FAD), which consists of } 12 \text { items that measure } \\
\text { the overall functioning and health of a family } \\
\text { (Byles, Byrne, Boyle, \& Offord, 1988; Epstein, } \\
\text { Baldwin, \& Bishop, 1983). A score is given to } \\
\text { each item from one to four, depending on } \\
\text { the individual's response to a certain } \\
\text { statement, which is then averaged. A } \\
\text { total score of two or more is considered } \\
\text { as problematic family functioning, } \\
\text { where the higher the score, the more } \\
\text { problematic the family's overall functioning } \\
\text { (Byles et al., 1988). }\end{array}$ & $\begin{array}{l}\text { A 4-point Likert Scale is used, which includes } \\
4 \text { options: strongly agree, agree, disagree and } \\
\text { strongly disagree. The responses for each } \\
\text { measure are added and the total is divided } \\
\text { by the number of items in each scale. The } \\
\text { higher the score, the worse the levels of family } \\
\text { functioning. }\end{array}$ \\
\hline Social Functioning Scale (SFS) & $\begin{array}{l}\text { Consists of six items measuring levels of } \\
\text { social conflict and financial hardship, time } \\
\text { spent with drug users and non-drug users } \\
\text { and involvement in criminal activity } \\
\text { (Lawrinson et al., 2005). A scoring from } \\
\text { zero to three is provided and then summed. } \\
\text { A higher score represents a greater degree } \\
\text { of social dysfunction (Darke, Hall, Wodak, } \\
\text { Heather, \& Ward, 1992; Epstein et al., 1983; } \\
\text { Lawrinson et al., 2005). }\end{array}$ & $\begin{array}{l}\text { A scoring from zero to three is provided for } \\
\text { each question, where all scores are summed. } \\
\text { Some answers my not be applicable to some } \\
\text { people so a coefficient based on non-applicable } \\
\text { answers is multiplied by the sum-total } \\
\text { (Darke et al., 1992; Epstein et al., 1983; } \\
\text { Lawrinson et al., 2005). }\end{array}$ \\
\hline
\end{tabular}

having been arrested in the preceding 3 months before admission compared with follow-up.

To measure statistical significance of ordinal variables, the Wilcoxon Signed Ranks Test was used with a cut off of $p<0.05$ for significance. Analyses using Wilcoxon Signed Ranks Test applied to: frequency of alcohol and polydrug use; and scores from the Severity of Dependence Scale (SDS), Family Assessment Device (FAD) and Social Functioning Scale (SFS) with IBM SPSS Statistics Version 17 used to analyse the data.

\section{Results}

From 2007 to 2016, 619 Aboriginal and Torres Strait Islander young people were admitted to the program; 247 stayed in the program for 30 days or more; 89 were successfully followed up 3 months post-discharge (36\% response rate). Of the 89 followed up, 82 self-identified as Aboriginal (92.1\%), three as Torres Strait Islander (3.3\%) and four as both Aboriginal and Torres Strait Islander $(4.6 \%)$.

\section{Description of study sample}

As shown in Table 2, young males are significantly more likely than young females to come into the Programme for Adolescent Life Management (PALM) under a court order, chi-square $X^{2}(1)=7.30, p=.007$. There were no other differences between males and females. The table also shows males (36\%) and females (50\%) commonly reported living in three or more places in the past 6 months.

\section{Comparison with adolescents lost to follow up}

Given that only 89 of the original 247 (36.0\%) Aboriginal and/or Torres Strait Islander adolescents who stayed in the program for 30 days or more were successfully followed up, it was considered important to compare these 89 people against the 158 (64.0\%) who could not be followed up on key study variables. Of the original 247 people, there were 59 young women $(23.9 \%)$ and 188 young men $(76.1 \%)$, of which a higher proportion of young women were followed up ( $n=30 ; 51 \%)$ compared with young men $(n=59 ; 31 \%)$, (Pearson chi-square $=7.38, \mathrm{df}=1, p=.007$ ). There were otherwise no significant differences between those who were followed up $(n=89)$ and those who could not be followed up $(n=158)$ across key variables: arrests in the last 3 months (Pearson chi-square $=0.79, \mathrm{df}=1$, $p=.374$ ), suicide attempt (Pearson chi-square $=1.32$, $\mathrm{df}=1, p=.25)$ or self-harmed in the last 3 months 
Table 2 Demographic and other key information about the study sample $(N=89)$

\begin{tabular}{|c|c|c|c|c|}
\hline & Male & Female & Total & $\mathrm{P}(\mathrm{Sig})$ \\
\hline & $59(66.3 \%)$ & $30(33.7 \%)$ & $89(100.0 \%)$ & \\
\hline & $\mathrm{n}(\%)$ & $\mathrm{n}(\%)$ & $n(\%)$ & \\
\hline Engaged in employment or study before entering PALM & $23(62.2 \%)$ & $14(37.8 \%)$ & $37(100.0 \%)$ & 0.487 \\
\hline Places lived in the past 6 months & & & & 0.108 \\
\hline 1 or 2 places & $38(73.1 \%)$ & $12(30.0 \%)$ & $52(100.0 \%)$ & \\
\hline 3 or more places & $21(56.8 \%)$ & $16(43.2 \%)$ & $37(100.0 \%)$ & \\
\hline Court involved & $50(74.6 \%)$ & $17(25.4 \%)$ & $67(100.0 \%)$ & 0.0007 \\
\hline Days at Palm & & & & 0.504 \\
\hline 31 to 60 days & $28(70.0 \%)$ & $12(30.0 \%)$ & $40(100.0 \%)$ & \\
\hline \multirow[t]{2}{*}{ More than 60 days } & $31(63.3 \%)$ & $18(36.7 \%)$ & $49(100.0 \%)$ & \\
\hline & M (SD) & $M(S D)$ & M (SD) & \\
\hline Age at start of PALM & $16.68(0.99)$ & $16.46(1.01)$ & $16.63(1.00)$ & 0.147 \\
\hline
\end{tabular}

(Pearson chi-square $=0.05, \mathrm{df}=1, p=.831$ ), spending time with family (Pearson chi-square $=0.83, \mathrm{df}=1, p=.361$ ), time with friends who do not do drugs (Pearson chisquare $=2.83, \mathrm{df}=1, p=.093)$ and number of residences in the past 6 months (Pearson chi-square $=10.71, \mathrm{df}=5$, $p=.06)$. There was also no difference between the two groups in scores on the Severity of Dependence scale $(\mathrm{t}=0.23, \mathrm{df}=1,242, p=.822)$.

Among the population of Aboriginal and Torres Strait Islander young people who attended PALM for at least 30 days $(n=247)$, the number of days in residential treatment ranged from 20 to 120 days. The 89 participants in the study who were able to be followed up spent a significantly greater number of days in PALM $(M=66.01$; $\mathrm{SD}=21.05)$ compared with the 158 people who could not be followed up $(\mathrm{M}=56.82 ; \mathrm{SD}=22.56, \mathrm{t}(245)=-$ $3.15, p=.002$ ).

\section{Main results}

In the remaining set of analyses, baseline data (at commencement of PALM) are compared against follow-up data for the 89 Aboriginal and Torres Strait Islander adolescents who stayed in the program for 30 days or more and were successfully followed up.

\section{Drug use}

The proportion of Aboriginal and Torres Strait Islander young people who reported use of ATS, cannabis and tobacco in the last month was compared prior to admission and 3 months' post-discharge (Table 3). There was a significant change in the proportion of young people reporting the use of ATS 'once or more' in the month before admission compared with those reporting use in the previous month at follow up (exact McNemar's test $=11.172, \mathrm{df}=1, p<.001)$. As shown in Table 3, 27\% of young people reported using ATS prior to admission shifted to reporting 'no' use of ATS after attending the program - a positive shift. Even though there were 5.6\% young people who reported using ATS at 3 months post discharge compared to prior to admission, there was a significantly greater proportion stopping than starting the use of ATS. Of the young people reporting no change in their ATS use - 57.3\% reported 'no' use of ATS both prior to admission and 3 months after discharge from the program, while $10.1 \%$ reported using ATS 'once or more' both before and 3 months postdischarge.

Similarly, there was a significant difference in the proportion of young people reporting using cannabis 'once or more' in the month prior to admission compared with reporting at 3 months' post-discharge (exact McNemar's test $=11.115, \mathrm{df}=1, p<.001)$ (Table 3 ). There was a significantly greater proportion stopping than starting the use of cannabis, following the program. About $25 \%$ of young people reported using cannabis before admission and subsequently reported 'not' using cannabis 3 months post-discharge. In comparison, $4.5 \%$ of young people reported not using cannabis in the month prior to admission and shifted to using cannabis at 3 months' postdischarge. Most young people (64\%) reported cannabis use both before and after the program.

There was no significant difference in the proportion of young people who stopped or started using tobacco (exact McNemar's test $=0.0435, \mathrm{df}=1, p=1.00$ ) (Table 3). Many of the young people $(67.4 \%)$ reported using tobacco both before and after the program.

The frequency of alcohol and polydrug use prior to and at 3 months' post-discharge was analysed and is presented in Table 4 . There was a significant difference (Wilcoxon signed ranks test $\mathrm{z}=-4.173, p<.001$ ) in the number of days young people reported drinking alcohol in the last month (Table 4), with a decrease in the 
Table 3 Treatment outcomes at three-month post-discharge (versus pre-admission)

\section{Used once or more in the last month}

Three months post-discharge

$\begin{array}{llll}\text { Pre admission } & \text { Yes } & \text { No } & \begin{array}{l}\text { Total } \\ n(\%)\end{array} \\ \text { ATS } & n(\%) & n(\%) & 33(37.1 \%) \\ \text { Yes } & 9(10.1 \%) & 24(27.0 \%) & 56(62.9 \%) \\ \text { No } & 5(5.6 \%) & 75(87.3 \%) & 89(100 \%) \\ \text { Total } & 14(15.7 \%) & & 79(88.8 \%) \\ \text { Cannabis } & & 22(24.7 \%) & 10(11.2 \%) \\ \text { Yes } & 57(64.0 \%) & 6(6.7 \%) & 89(100 \%) \\ \text { No } & 4(4.5 \%) & 28(31.5 \%) & 72(80.9 \%) \\ \text { Total } & 61(68.5 \%) & & 17(19.1 \%) \\ \text { Tobacco } & & 6(13.5 \%) & 89(100 \%) \\ \text { Yes } & 60(67.4 \%) & 18(20.2 \%) & \\ \text { No } & 11(12.4 \%) & 71(79.8 \%) & \end{array}$

Spending time with family and with friends who do not use drugs

Three months post discharge

Pre admission

Spending time with family

$\begin{array}{ll}\text { No/little time } & 37(41.6 \%) \\ \text { Fair amount/ a lot of time } & 14(15.7 \%) \\ \text { Total } & 51(57.3 \%)\end{array}$

Spending time with friends who do not use drugs

$\begin{array}{ll}\text { No/little time } & 59(66.3 \%) \\ \text { Fair amount/ a lot of time } & 8(9.0 \%) \\ \text { Total } & 67(75.3 \%)\end{array}$

\section{Attempted to end life or self-harmed}

Pre admission

Yes

n (\%)

$0(0.0 \%)$

$3(3.4 \%)$

$3(3.4 \%)$

Total

Self-harmed in the last three months

Yes

No

Total
No/little time n (\%)

$67(75.3 \%)$
Fair amount/ a lot of time n (\%)

$14(15.7 \%)$

$24(27.0 \%)$

$38(42.7 \%)$

$19(21.3 \%)$

$3(3.4 \%)$

$22(24.7 \%)$
Total

n (\%)

$51(57.3 \%)$

$38(42.7 \%)$

89 (100\%)

$78(87.6 \%)$

$11(12.4 \%)$

$89(100 \%)$

Three months post discharge

$\begin{array}{ll}\text { No } & \text { Total } \\ \text { n (\%) } & n(\%) \\ 18(20.2 \%) & 18(20.2 \%) \\ 68(76.4 \%) & 71(79.8 \%) \\ 86(96.6 \%) & 89(100 \%) \\ & \\ 23(25.8 \%) & 27(30.3 \%) \\ 60(67.4 \%) & 62(69.7 \%) \\ 83(93.3 \%) & 89(100 \%)\end{array}$


Table 3 Treatment outcomes at three-month post-discharge (versus pre-admission) (Continued)

\begin{tabular}{|c|c|c|c|}
\hline \multicolumn{4}{|c|}{ Currently engaged in work or study } \\
\hline \multicolumn{4}{|c|}{ Three months post discharge } \\
\hline Pre admission & $\begin{array}{l}\text { Yes } \\
\text { n (\%) }\end{array}$ & $\begin{array}{l}\text { No } \\
n(\%)\end{array}$ & $\begin{array}{l}\text { Total } \\
\text { n (\%) }\end{array}$ \\
\hline Yes & $22(24.7 \%)$ & $15(16.9 \%)$ & $37(41.6 \%)$ \\
\hline No & $16(18.0 \%)$ & $36(40.4 \%)$ & $52(58.4 \%)$ \\
\hline Total & $38(42.7 \%)$ & $51(57.3 \%)$ & $89(100 \%)$ \\
\hline \multicolumn{4}{|c|}{ Number of arrests in the last 3 months } \\
\hline \multicolumn{4}{|c|}{ Three months post-discharge } \\
\hline Pre admission & $\begin{array}{l}\text { None } \\
\mathrm{n}(\%)\end{array}$ & $\begin{array}{l}\text { One or more } \\
\mathrm{n}(\%)\end{array}$ & $\begin{array}{l}\text { Total } \\
\text { n (\%) }\end{array}$ \\
\hline None & $16(19.3 \%)$ & $4(4.8 \%)$ & $20(24.1 \%)$ \\
\hline One or more & $39(47.0 \%)$ & $24(28.9 \%)$ & $63(75.9 \%)$ \\
\hline Total & 55 (66.3\%) & 28 (33.7\%) & 83 (100\%) \\
\hline
\end{tabular}

median days of alcohol use from 3 days reported 3 months' post-program discharge compared to baseline, which had a median of 8 days. Between pre-and postprogram measures, 52 young people reduced the number of days of alcohol use while 22 young people increased the number of days they used alcohol. Fifteen young people reported no change in the number of days of alcohol use between pre and post program.

There was a significant overall reduction (Wilcoxon signed ranks test $\mathrm{z}=-4.985, p<.001$ ) in the number of drugs used prior to admission and 3 months postdischarge, as shown in Table 4. Comparing the number of drugs used pre and post, 51 young people reported a reduction in the number of drugs used, while 15 reported an increase, and 23 young people reported using the same number of drugs before and 3 months after program discharge.

The Severity of Dependence Scale (SDS) median score prior to admission was 8.00 which significantly decreased to 4.50 at three-month follow-up (Wilcoxon signed ranks test $\mathrm{z}=-6.050, p<.001)$. Among the young people, the median score decreased for 67, increased for 11 and stayed the same for 2 people (Table 4). However, the post-discharge median of 4.50 is still indicative of problematic alcohol and drug use.

\section{Social and family functioning}

Change in scores on two scales prior to and at 3 months' post-discharge from the program was analysed (Table 4). There was no significant reduction in the mean scores on the Family Assessment Device (FAD) from baseline to three-month follow-up (Wilcoxon signed ranks test $\mathrm{z}=-1.693, p=.090)$ and no significant difference in the Social Functioning Scale (SFS) mean score (Wilcoxon signed ranks test $\mathrm{z}=-1.493, p=.136)$ prior compared to post-discharge.

There were no significant changes in the reporting of time spent with family before admission and 3 months post-discharge (exact McNemar's test $=0.000, \mathrm{df}=1, p=$ 1.00) (Table 3). There was also no significant change in the number reporting time spent with friends who did not do drugs prior to admission and 3 months' post-discharge,

Table 4 Changed scores on SDS, FAD and SFS scales and alcohol frequency and polydrug use prior to and at 3 months post discharge

\begin{tabular}{|c|c|c|c|c|c|c|c|c|c|}
\hline & \multicolumn{2}{|l|}{ Pre-admission } & \multicolumn{2}{|c|}{ Three months post discharge } & \multirow{2}{*}{$\begin{array}{l}\text { Positive } \\
\text { ranks }\end{array}$} & \multirow{2}{*}{$\begin{array}{l}\text { Negative } \\
\text { ranks }\end{array}$} & \multirow[t]{2}{*}{ Ties } & \multirow[t]{2}{*}{ Z } & \multirow[t]{2}{*}{$P$} \\
\hline & Median & IQR & Median & IQR & & & & & \\
\hline SDS & $8.00(N=80)$ & 4.00 & $4.50(N=80)$ & 6.00 & 67 & 11 & 2 & -6.050 & 0.000 \\
\hline FAD & $2.50(N=57)$ & 0.50 & $2.42(N=57)$ & 0.54 & 31 & 23 & 3 & -1.693 & 0.090 \\
\hline SFS & $10.8(N=75)$ & 6.60 & $10.5(N=75)$ & 3.60 & 40 & 30 & 5 & -1.493 & 0.136 \\
\hline Alcohol frequency & $8.00(N=89)$ & 19.00 & $3.00(N=89)$ & 10.00 & 52 & 22 & 15 & -4.173 & 0.000 \\
\hline Polydrug use & $2.00(N=89)$ & 2.00 & $2.00(N=89)$ & 1.00 & 51 & 15 & 23 & -4.985 & 0.000 \\
\hline
\end{tabular}


(exact McNemar's test $=3.704, \mathrm{df}=1, p=.052$ ). The majority of young people (66.3\%) spent no or little time with friends who did not use drugs at both baseline and at 3 months' follow-up.

\section{Suicide and self-harm}

There was a significant change between pre-and postreported suicide attempts by Aboriginal and Torres Strait Islander young people, (exact McNemar's test = $30.422, \mathrm{df}=1, p<.001)$ in the direction of fewer people attempting suicide at follow-up compared with baseline (Table 3$)$. All 18 (20.2\% of the sample) young people who reported attempting suicide in the 3 months prior to admission, reported no suicide attempts during the 3 months post discharge. There was also a significant reduction in the number of Aboriginal and Torres Strait Islander young people who reporting self-harming in the previous 3 months compared with follow up (exact McNemar's test $=17.640, \mathrm{df}=1, p<.001)$. Twenty-three young people (out of the 27 who reported self-harming in the 3 months prior to admission) reported no selfharming in the 3 months' post discharge.

\section{Employment/study and engagement in crime}

Aboriginal and Torres Strait Islander young people's engagement in work or study and arrests in the previous 3 months were compared pre-and post-program (Table 3). There was no significant change in engagement in work or study prior to admission to the program and 3 months post-discharge (exact McNemar's test $=0.000$, $\mathrm{df}=1, p=1.00)$. However, there was a significant decrease in the proportion who reported being arrested prior to admission and 3 months post-discharge (exact McNemar's test $=26.884, \mathrm{df}=1, p<.001)$. There were $47 \%$ of young people who reported one or more arrests prior to admission, shifting to reporting no arrests 3 months post-discharge. This was a greater proportion than the $4.8 \%$ of young people who reported no arrests in the 3 months prior to the program and were arrested during the 3 months post discharge.

\section{Discussion}

This study examined how Aboriginal and Torres Strait Islander young people, following 30 or more days in a 'mainstream' residential drug and alcohol treatment program were faring after treatment. The analysis compared data at admission to community follow-up at least 3 months post-discharge. To our knowledge, this is the first study to undertake treatment follow-up measures with this population.

This study demonstrates therapeutic communities are an intervention worthy of further examination in relation to preventing self-harm and suicide among Aboriginal and/or Torres Strait Islander people, whose rates are among the highest in the world (Dudgeon et al., 2016). This study found a significant decrease in self-harm post compared to prior to the program among those who were able to be followed up. Reported suicide attempts also significantly decreased. However, it is important to acknowledge that attempted suicide or self-harm may have been the catalyst for entering the program, which may create a reversion to the mean as suicide attempts and self-harm may reduce regardless of the program.

Significantly fewer Aboriginal and Torres Strait Islander young people reported using alcohol again since completing the program, with fewer days using alcohol for those who continued to drink. Number of drugs used, and frequency also significantly reduced, and the Severity of Dependence Scale scores significantly improved. These results suggest the program and its components have contributed to reducing drug and alcohol use for at least some of the Aboriginal and Torres Strait Islander young people who participated in the program. Despite a significant reduction in the number using cannabis post treatment compared to baseline, $64 \%$ of the sample were still using cannabis at follow up. The reasons for the lack of impact on the use of cannabis among these young people requires further research. The improvements in life circumstances and reductions in related problems surrounding alcohol and drug use, such as arrests were found. It is well-known that Aboriginal and Torres Strait Islander young people are overrepresented in youth detention, with a majority in adult prisons having previous periods of incarceration (ABS, 2017; Fox et al., 2013; Whitesell et al., 2013). The specific role of this program in possibly contributing to a reduction in arrests requires further investigation. Research shows imprisonment is costly not only to governments, but also to prospects of genuine rehabilitation as it erodes individual and community health (Francis, Cheryl Lero, \& Daniel, 2011).

There were no significant differences for Aboriginal and Torres Strait Islander young people spending time with friends who did not use drugs or spending a fair or a lot of time with family pre-to post program. A change to peer networks can be important post treatment given the potential influence peer groups can have on young people's drug and alcohol use (Brown et al., 2008; Engels, 2003). The reason why this change in peer networks did not occur for many of the young people in this study is not able to be determined from the current study data, but it may be the case that it takes more time than 3 months for young people to make connections with other young people who don't use drugs. This may also be more challenging for Aboriginal young people as friends who use drugs may include those with whom they have kinship connections (Bennett et al., 2013). 
The finding that time spent with family, often seen as an important source of support (Tsey et al., 2010), did not change is important and not necessarily a negative finding. For some young people, their family of origin may be a source of stress, and time away from them whilst in a TC and in the first few months post treatment discharge may help reduce pressure on relationships and contribute to improving family dynamics in the longer term (King et al., 2009; Waldram, Herring \& Young., 2006). For those who did spend time with family, no significant improvements were recorded using the Family Assessment Device (FAD) 3 months after program discharge compared to before admission. With mean scores remaining above the clinically significant threshold, family is clearly a potential stressor for many of the young people who were in the program, as evident in other studies with Indigenous peoples' (King, Smith \& Gracey., 2009; Waldram, Herring \& Young., 2006). Further attention to understanding the impact of family relationships in treatment and after care are needed. This is particularly important for Aboriginal and Torres Strait Islanders among whom 'family' often includes extended networks, not only immediate blood relatives. Aboriginal and Torres Strait Islander people have particularly enduring and instrumental kinship connections vital for identity, belonging and cultural knowledge transfer (Bennett et al., 2013), which helps to counter frequent experiences of racism (Tsey et al., 2010) reduce alcohol and drug use and develop resilience and strength (Brady, 1995). The conceptualisation of family in the tool used in the current study may not capture the broader notion of family for many Aboriginal and/or Torres Strait Islander people.

The loss to follow-up in this study is a limitation. Loss to follow-up is an issue in many adolescent drug and alcohol treatment studies (Tripodi, 2009; Williams \& Chang, 2000) and this is likely to be more challenging when these young people also identify as Indigenous. It is possible that the subgroup of program participants who were doing well post treatment compared to those who were not were more likely to respond to a follow-up survey request. However, even though the follow up group may not have been representative of all those who stayed 30 days or more, the findings that there was a significant reduction in key harms, including self-harm, suicide attempts, substance use and arrests is nonetheless an important contribution to the field. There is a complete lack of published data on Aboriginal and Torres Strait Islander young people following residential drug and alcohol treatment and the current study suggests there could be positive outcomes for these young people from such programs. However, based on the current study design, causality cannot be attributed to the program, and any improvements could also be due to time or some other factor not measured in the study.

A comparison was made between those who were followed up and those lost to follow up and no differences were found on key socio-demographic measures or among key variables which were the focus of the analysis except that a higher proportion of young women were followed up compared with young men. This is a limitation of the study. Young men are possibly harder to follow up in the community as at baseline young men were significantly more like to be court involved than young women and this difference may persist post treatment for those young men lost to follow up. Additionally, those lost to follow up had a significantly shorter length of stay than those who were followed up.

The current study was focussed on those who had a length of stay of 30 days or more given the relationship between length of stay and outcomes (Darke et al., 2012; Edelen et al., 2010; Galaif et al., 2001; Mills et al., 2013; Orlando et al., 2003). A further analysis of the factors associated with retention in programs for Aboriginal and Torres Strait Islander young people would be useful to inform program design to better meet client needs and improve length of stay.

A further limitation is that the measures used were not developed specifically for Aboriginal and Torres Strait Islander young people. The service has used the best available and accepted measures in the field and the psychosocial measures have been validated in a range of studies as detailed in Table 1. Further, the changes found pre/post in the current study were in response to direct questions asking about behaviours, such as drug use, arrests, and self-harm rather than psychological scales with multiple items. Where scales were measuring more complex constructs, such as family functioning, we found no change, and this may or may not reflect a problem with the scale itself and its applicability to Aboriginal and Torres Strait Islander young people as discussed above. The strengths of this study include the co-design and collaboration with Aboriginal community organisations.

\section{Implications and future directions}

Findings of this study provide some support for the capacity of 'mainstream' drug and alcohol residential treatment programs to provide positive outcomes for Aboriginal and Torres Strait Islander young people. Culturally-relevant modes of treatment and support are particularly important when Aboriginal and Torres Strait Islander young people are over-represented in the client group compared to in the community population (Gray et al., 2014; Taylor et al., 2010) as is the case with this program. In addition, there is a need to formally review programs to understand how they incorporate culturally relevant modes of caregiving to 
improve outcomes among young Aboriginal and Torres Strait Islander people. There is also a need to develop a robust tool for the measurement of outcomes post drug and alcohol treatment specifically for young people, including domains of life improvement that may be particularly relevant for those who identify as Aboriginal and Torres Strait Islander.

\section{Conclusion}

This study followed up Aboriginal and Torres Strait Islander young people after attending a residential alcohol and drug treatment program in Australia. Given the limited evidence about outcomes among these young people following treatment, this study makes and important contribution to the field. Several significant improvements were found in reduced drug use, arrests, self-harm and reported suicide attempts, although study limitations suggest caution in attributing changes directly to the program. Nonetheless, the study provides some evidence for the effectiveness of a residential treatment program using a Therapeutic Community approach for Aboriginal and Torres Strait Islander young people with problematic drug and alcohol use.

\section{Abbreviations}

ABS: Australian Bureau of Statistics: AlHW: Australian Institute of Health and Welfare; ATS: Amphetamine type stimulants; CoA: Council of Australian Governments; FAD: Family Assessment Device; MCDS: Ministerial Council on Drug Strategy; PALM: Program for Adolescent Life Management; SDS: Severity of Dependence Scale; SFS: Social Functioning Scale;

TC: Therapeutic Community

\section{Acknowledgements}

Staff and residents of the treatment facilities for their support and cooperation in the research.

\section{Authors' contributions}

KM and PR undertook the statistical analysis with input from SN. MW, KM and SN drafted the paper with PR and KP also providing feedback and editing of content. All authors reviewed and approved the final manuscript.

\footnotetext{
Authors' information

$\mathrm{SN}$ is a Senior Lecturer at the School of Public Health and Community Medicine, UNSW Sydney and is a social scientist who uses qualitative and quantitative methods in her research. SN works closely with service-provider organisations with focus areas including advocacy by the non-government sector, capacity building for health development, adolescent drug and alcohol treatment and Aboriginal health and well-being. KM has a Master of International Public Health and now works as a consultant, implementing Electronic Medical Record systems in hospitals around Australia. MW is an Associate Professor and Head of the Indigenous Health Discipline at the Graduate School of Health at UTS, Sydney. She has over 20 years' experience combining health service delivery and research, particularly focusing on Aboriginal peoples' leadership to improve the health and wellbeing of people in the criminal justice system and post-prison release. She is a Wiradjuri descendent, and has Anglo-Celtic heritage. KP is the Clinical Services Manager for the Ted Noffs Foundation, responsible for the clinical and training oversite of Noffs programs nationwide. He is a registered psychologist and has undertaken further qualifications in management. PR is a Senior Lecturer in the School of Public Health \& Community Medicine, UNSW. His research interests include behavioural surveys, quantitative methods and data analysis with vulnerable groups.
}

\section{Funding}

This research was supported by an Australian Research Council Linkage Projects funding grant (LP140100429) and the Ted Noffs Foundation.

\section{Availability of data and materials}

This publication has used sensitive health information. Except in the form of conclusions drawn from the data, researchers do not have permission to disclose any data to any person other than those authorised for the research project.

\section{Ethics approval and consent to participate}

Approval was received from the Human Research Ethics Committee (HREC) of the University of New South Wales (UNSW) (Ref: HC13014) and the Aboriginal Health and Medical Research Council (Ref: 1144/15). An Aboriginal Advisory Committee guided the study, with representatives of Aboriginal organisations, researchers, staff and young people who have completed the program. All young people consented to their data being used in research.

\section{Consent for publication}

This paper has been reviewed and approved by the Aboriginal Health and Medical Research Council and the Aboriginal Advisory Committee.

\section{Competing interests}

Kieran Palmer is an employee of the Ted Noffs Foundation, which operates the treatment programs which provided the client data for this study. Ted Noffs Foundation staff have not been directly involved in the analysis of the data. Kieran Palmer as an author has contributed to the write up of the findings by providing service provider insights. The Ted Noffs Foundation are also a signatory to an Australian Research Council Funding Grant (LP140100429) and associated contract. In this contract, Ted Noffs have stated their commitment to acting on the findings of the research undertaken in this study, both positive and negative, about their programs. No other authors have a conflict of interest to declare.

\section{Author details}

${ }^{1}$ School of Public Health and Community Medicine, UNSW, Sydney, Australia. ${ }^{2}$ Graduate School of Health, University of Technology, Sydney, Australia. ${ }^{3}$ Ted Noffs Foundation, Sydney, Australia.

Received: 14 July 2019 Accepted: 10 January 2020

Published online: 07 February 2020

\section{References}

ABS. (2014). Exploring the gap in labour market outcomes for Aboriginal and Torres Strait Islander peoples. Retrieved from Australian Bureau of Statistics, Canberra, Australia on 1 June 2019: https://www.abs.gov.au/ausstats/abs@. nsf/Lookup/4102.0main+features72014

ABS. (2016). Census of population and housing: Reflecting Australia-Stories from the Census, 2016. Retrieved from Australian Bureau of Statistics, Canberra, Australia on 1 June 2019: http://www.abs.gov.au/ausstats/abs@.nsf/Lookup/ by\%20Subject/2071.0 2016 Main\%20Features Aboriginal\%20and\%2 0Torres\%20Strait\%20lslander\%20Population\%20Data\%20Summary 10

ABS. (2017). Prisoners in Australia, 2016. Retrieved from Australian Bureau of Statistics, Canberra, Australia on 1 June 2019:http://www.abs.gov.au/ausstats/ abs@.nsf/Lookup/by\%20Subject/4517.0 2016 Main\%20Features Aboriginal\%20and\%20Torres\%20Strait\%20lslander\%20prisoner\%2 Ocharacteristics 5

AlHW. (2011a). Drugs in Australia 2010. Retrieved from the Australian Institute of Health and Welfare, Canberra, Australia on 1 June 2019: https://www.aihw. gov.au/reports/alcohol-other-drug-treatment-services/drugs-in-australia-2010/ contents/table-of-contents

AlHW. (2011b). Substance use among Aboriginal and Torres Strait Islander people. Retrieved from the Australian Institute of Health and Welfare, Canberra, Australia on 1 June 2019: http://www.aihw.gov.au/WorkArea/ DownloadAsset.aspx?id=10737418265

AlHW. (2014). National Drug Strategy Household Survey detailed report 2013. Retrieved from the Australian Institute of Health and Welfare, Canberra, Australia on 1 June 2019:http://www.aihw.gov.au/WorkArea/DownloadAsset. aspx?id=60129549848.

AlHW. (2015). The health and welfare of Australia's Aboriginal and Torres Strait Islander peoples. Retrieved from the Australian Institute of Health and 
Welfare, Canberra, Australia on 1 June 2019:http://www.aihw.gov.au/ WorkArea/DownloadAsset.aspx?id=60129551281.

AlHW. (2016). Child protection Australia 2014-15. Retrieved from the Australian Institute of Health and Welfare, Canberra, Australia on 1 June 2019: http:// www.aihw.gov.au/publication-detail/?id=60129554728

AlHW. (2019). Alcohol and other drug treatment services in Australia 2017-18. In Drug treatment series no. 33. Cat. No. HSE 230 Retrieved from the Australian Institute of Health and Welfare, Canberra, Australia on 1 June 2019: https:// www.aihw.gov.au/reports/alcohol-other-drug-treatment-services/aodts-201 7-18-key-findings/contents/summary.

American Psychiatric Association. (2013). Substance-related and addictive disorders. In Diagnostic and statistical manual of mental disorders (DSMIV). Washington, DC: American, Psychiatric Association.

Atkinson, C. (2009). The violence continuum: Australian Aboriginal male violence and generational posttraumatic stress (9783838321721). Retrieved from Darwin, Australia on 1 June 2019: http://espace.cdu.edu.au/view/cdu:44891

Atkinson, J. (2002). Trauma trails, recreating song lines: the transgenerational effects of trauma in indigenous Australia (1876756225). Retrieved on 1 June 2019 from: https://epubs.scu.edu.au/gnibi_pubs/2/

Attwood, B. (2005). Telling the truth about Aboriginal history. Australia: Allen \& Unwin.

Australian Department of Health. (2011). The National Drug Strategy 2010-2015. Retrieved on 1 June 2019 from the Australian Department of Health Canberra, Australia: http://www.nationaldrugstrategy.gov.au/internet/ drugstrategy/Publishing.nsf/content/DB4076D49F13309FCA257854007BAF30/ \$File/nds2015.pdf

Australian Department of Health. (2013). National Aboriginal and Torres Strait Islander Health Plan 2013-2023. Retrieved from Retrieved from Australian Department of Health, Canberra, Australia on 1 June 2019:https://www1. health.gov.au/internet/main/publishing.nsf/Content/natsih-plan

Battjes, R. J., Gordon, M. S., O'Grady, K. E., Kinlock, T. W., Katz, E. C., \& Sears, E. A. (2004). Evaluation of a group-based substance abuse treatment program for adolescents. Journal of Substance Abuse Treatment, 27(2), 123-134.

Bennett, B., Green, S., Gilbert, S., \& Bessarab, D. (2013). Our voices : Aboriginal and Torres Strait islander social work. Melbourne: South Yarra Palgrave Macmillan.

Brady, M. (1995). Giving away the grog: Aboriginal accounts of drinking and not drinking. Retrieved on 1 June 2019 from commonwealth Department of Human Services and Health, Canberra. https://catalogue.nla.gov.au/ Record/2257319

Brown, S. A., McGue, M., Maggs, J., Schulenberg, J., Hingson, R., Swartzwelder, S., et al. (2008). A developmental perspective on alcohol and youths 16 to 20 years of age. Pediatrics, 121(Suppl 4), S290-S310. https://doi.org/10.1542/peds. 2007-2243D

Burgess, C. P., \& Johnstone FH. (2007). Indigenous natural and cultural resource management and health. Retrieved on 1 June 2019 from: http://www.arlash.com/wp-content/uploads/2014/08/ IndigenousNationalandCulturalResourceManagementandHealth1.pdf

Byles, J., Byrne, C., Boyle, M. H., \& Offord, D. R. (1988). Ontario child health study: Reliability and validity of the general functioning subscale of the McMaster family assessment device. Family Process, 27(1), 97-104.

CoA. (2017). Closing the Gap's Prime Minister's Report 2017. Commonwelath of Australia (CoA) Retrieved on 1 June 2019 from Canberra, Australia: http:// closingthegap.pmc.gov.au/sites/default/files/ctg-report-2017.pdf

Darke, S., Campbell, G., \& Popple, G. (2012). Retention, early dropout and treatment completion among therapeutic community admissions. Drug and Alcohol Review, 31, 64-71. https://doi.org/10.1111/j.14653362.2011.00298.x

Darke, S., Hall, W., Wodak, A., Heather, N., \& Ward, J. (1992). Development and validation of a multi-dimensional instrument for assessing outcome of treatment among opiate users: The opiate treatment index. British Journal of Addiction, 87(5), 733-742.

De Leon, G. (2000). The therapeutic community: theory, model and method. New York: Springer publishing company.

Dixson, G., Woolfenden, S., Jayasinha, R., Rawstorne, P., Palmer, K., \& Nathan, S. (2018). Characteristics of Australian adolescent females in residential treatment who report using methamphetamines. Drug and Alcohol Review, 37(S1), S384-S393. https://doi.org/10.1111/dar.12641

Dudgeon, P., Milroy, J., Calma, T., Luxford, Y., Ring, I., Walker, R., Cox, A., Georgatos, G., \& Holland, C. (2016). Solutions that work: What the evidence and our people tell us: Aboriginal and Torres Strait Islander Suicide Prevention
Evaluation Project Report. Retrieved on 1 June 2019 from the University of Western Australia: https://www.atsispep.sis.uwa.edu.au/__data/assets/pdf_file/ 0006/2947299/ATSISPEP-Report-Final-Web.pdf

Edelen, M. O., Slaughter, M. E., McCaffrey, D. F., Becker, K., \& Morral, A. R. (2010). Long-term effect of community-based treatment: Evidence from the adolescent outcomes project. Drug and Alcohol Dependence, 107(1), 62-68.

Elder, B. (2003). Blood on the wattle: Massacres and maltreatment of aboriginal Australians since 1788. Sydney: New Holland.

Elias, B., Mignone, J., Hall, M., Hong, S. P., Hart, L., \& Sareen, J. (2012). Trauma and suicide behaviour histories among a Canadian indigenous population: An empirical exploration of the potential role of Canada's residential school system. Social Science \& Medicine, 74(10), 1560-1569. https://doi.org/10.1016/j.socscimed.2012.01.026.

Engels, R. C. M. E. (2003). Beneficial functions of alcohol use in adolescents: Theory and implications for prevention. Nutrition Today, 38(1), 25-30.

Epstein, N. B., Baldwin, L. M., \& Bishop, D. S. (1983). The McMaster family assessment device. Journal of Marital and Family Therapy, 9(2), 171-180. https://doi.org/10.1111/j.1752-0606.1983.tb01497.x.

Falck, R. S., Nahhas, R. W., Li, L., \& Carlson, R. G. (2012). Surveying teens in school to assess the prevalence of problematic drug use. Journal of School Health, $82,217-224$.

Fox, T. P., Oliver, G., \& Ellis, S. M. (2013). The destructive capacity of drug abuse: An overview exploring the harmful potential of drug abuse both to the individual and to society. ISRN Addiction, 2013, 6. https://doi.org/10.1155/ 2013/450348.

Francis, T. C., Cheryl Lero, J., \& Daniel, S. N. (2011). Prisons do not reduce recidivism: The high cost of ignoring science. The Prison Journal, 91(3_suppl), 48S-65S. https://doi.org/10.1177/0032885511415224.

Galaif, E. R., Hser, Y.-I., Grella, C. E., \& Joshi, V. (2001). Prospective risk factors and treatment outcomes among adolescents in DATOS-A. Journal of Adolescent Research, 16(6), 661-678. https://doi.org/10.1177/ 0743558401166008

Galea, S., Nandi, A., \& Vlahov, D. (2004). The social epidemiology of substance use. Epidemiologic Reviews, 26(1), 36-52. https://doi.org/10.1093/epirev/mxh007.

Gray D, Saggers S, Atkinson D \& Wilkes E (2008). Substance misuse. In: Couzos S \& Murray R (eds). Aboriginal primary health care: an evidencebased approach. 3rd edn. Melbourne: Oxford University Press.

Gray, D., Wilson, M., Allsop, S., Saggers, S., Wilkes, E., \& Ober, C. (2014). Barriers and enablers to the provision of alcohol treatment among aboriginal Australians: A thematic review of five research projects. Drug and Alcohol Review, 33(5), 482-490. https://doi.org/10.1111/dar.12137.

Haswell, M. R., Blignault, I., Fitzpatrick, S., \& Jackson Pulver, L. . (2013). The social and emotional wellbeing of indigenous youth: Reviewing and extending the evidence and examining implications for policy and practice. Retrieved on 1 June 2019 from University of Western Sydney, Sydney, Australia: https://researchdirect.westernsydney.edu.au/islandora/ object/uws:33498

Hser, Y., Grella, C. E., Hubbard, R. L., Hsieh, S., Fletcher, B. W., Brown, B. S., \& Anglin, M. D. (2001). An evaluation of drug treatments for adolescents in 4 US cities. Archives of General Psychiatry, 58(7), 689.

Human Rights and Equal Opportunities Commission. (1997). Bringing them home: National Inquiry into the separation of Aboriginal and Torres Strait Islander children from their families. Retrieved on 1 June 2019 from Human Rights and Equal Opportunities Commission Sydney, Australia: https://www. humanrights.gov.au/our-work/bringing-them-home-report-1997

Kidd, R. (1997). The way we civilise: Aboriginal Affairs- The untold story. Australia: University of Queensland Press.

King, M., Smith, A., \& Gracey, M. (2009). Indigenous health part 2: The underlying causes of the health gap. The Lancet, 374(9683), 76-85. https://doi.org/10. 1016/S0140-6736(09)60827-8.

Laliberté, A., Haswell-Elkins, M., \& Reilly, L. (2009). The healing journey: Empowering aboriginal communities to close the health gap. Australasian Psychiatry, 17(1_suppl), S64-S67. https://doi.org/10.1080/ 10398560902948704

Lawrinson, P., Copeland, J., Gerber, S., \& Gilmour, S. (2007). Determining a cut-off on the severity of dependence scale (SDS) for alcohol dependence. Addictive Behaviors, 32(7), 1474-1479. https://doi.org/10. 1016/j.addbeh.2006.09.005.

Lawrinson, P., Copeland, J., \& Indig, D. (2005). Development and validation of a brief instrument for routine outcome monitoring in opioid maintenance pharmacotherapy services: The brief treatment outcome measure (BTOM). 
Drug \& Alcohol Dependence, 80(1), 125-133. https://doi.org/10.1016/j. drugalcdep.2005.04.001.

Madden, R., Tickle, L., Jackson Pulver, L., \& Ring, I. T. (2012). Estimating indigenous life expectancy: Pitfalls with consequences. Journal of Population Research, 29(3), 229-247.

Martin, G., Copeland, J., Gates, P., \& Gilmour, S. (2006). The severity of dependence scale (SDS) in an adolescent population of cannabis users: Reliability, validity and diagnostic cut-off. Drug and Alcohol Dependence, 83(1), 90-93. https://doi.org/10.1016/j.drugalcdep.2005.10.014.

Mills, L., Pepler, D., \& Cribbie, R. A. (2013). Effectiveness of residential treatment for substance abusing youth: Benefits of the Pine River institute program. Residential Treatment for Children \& Youth, 30(3), 202-226. https://doi.org/10. 1080/0886571X.2013.819273

Muck, R., Zempolich, K. A., Titus, J. C., Fishman, M., Godley, M. D., \& Schwebel, R. (2001). An overview of the effectiveness of adolescent substance abuse treatment models. Youth \& Society, 33(2), 143-168.

Nagel, T., Robinson, G., Condon, J., \& Trauer, T. (2009). Approach to treatment of mental illness and substance dependence in remote indigenous communities: Results of a mixed methods study. The Australian Journal of Rural Health, 17(4), 174-182. https://doi.org/10.1111/j.1440-1584.2009.01060.x.

Nathan, S., Bethmont, A., Rawstorne, P. R., Ferry, M., \& Hayen, A. (2016). Trends in drug use among adolescents admitted to residential treatment in Australia. Medical Journal of Australia, 204(4), 149-150. https://doi.org/ 10.5694/mja15.01018

Nathan, S., Rawstorne, P., Hayen, A., Bryant, J., Baldry, E., Ferry, M., Williams, M., Shanahan. M., \& Jayasinha, R. et al. (2016). Examining the pathways for young people with drug and alcohol dependence: A mixed-method design to examine the role of a treatment programme. BMJ Open, 6(5). https://doi.org/ 10.1136/bmjopen-2015-010824

Orlando, M., Chan, K. S., \& Morral, A. R. (2003). Retention of court-referred youths in residential treatment programs: Client characteristics and treatment process effects. American Journal of Drug \& Alcohol Abuse, 29(2), 337-357.

Pearce, S., Scott, L., Attwood, G., Saunders, K., Dean, M., De Ridder, R., et al. (2017). Democratic therapeutic community treatment for personality disorder: Randomised controlled trial. The British Journal of Psychiatry, 210(2), 149-156.

Perkins, R. L. M. (2010). First Australians. Mebourne: The Miegunyah press.

Phillips, G. (2003). Addictions and healing in aboriginal country. Canberra: Aboriginal Studies Press.

Phillips, G. (2007). Healing and public policy. In J. Altman \& M. Hinkson (Eds.), Coercive reconciliation (pp. 141-150). Arena: Melbourne.

Pollock, N. J., Naicker, K., Loro, A., Mulay, S., \& Colman, I. (2018). Global incidence of suicide among indigenous peoples: A systematic review. BMC Medicine 16(1), 145. https://doi.org/10.1186/s12916-018-1115-6.

Pulver, L. J., Haswell, M., Ring, I., Waldon, J., Clark, W. Whetung, V. ... Sadana, R. (2010). Indigenous health - Australia, Canada, Aotearoa New Zealand, and the United States - laying claim to a future that embraces health for us all. World Health Report Background Paper (33), retrieved on 1 June 2019 from University of Western Sydney, Australia: https://researchdirect.westernsydney. edu.au/islandora/object/uws:35500.

Rowan, M., Poole, N., Shea, B., Gone, J. P., Mykota, D., Farag, M., et al. (2014). Cultural interventions to treat addictions in indigenous populations: Findings from a scoping study. Substance Abuse Treatment, Prevention, and Policy, 9(1), 34. https://doi.org/10.1186/1747-597x-9-34

Spooner, C., \& Hetherington, K. (2005). Social determinants of drug use. NDARC technical report no. 228 retrieved on 1 June 2019 from Sydney, Australia https://ndarc.med.unsw.edu.au/resource/social-determinants-drug-use

Spooner, C., Mattick, R. P., \& Noffs, W. (2001). Outcomes of a comprehensive treatment program for adolescents with a substance-use disorder. Journal of Substance Abuse Treatment, 20(3), 205-213. https://doi.org/10.1016/S07405472(01)00166-0

Strelein, L. (2009). Compromised jurisprudence: Native title cases since Mabo. Canberra: Aboriginal Studies Press.

Taylor, K., Thompson, S., \& Davis, R. (2010). Delivering culturally appropriate residential rehabilitation for urban indigenous Australians: A review of the challenges and opportunities. Australian and New Zealand Journal of Public Health, 34(Suppl 1), S36-S40. https://doi.org/10.1111/j.1753-6405.2010.00551.X.

Topp, L., \& Mattick, R. P. (1997). Choosing a cut-off on the severity of dependence scale (SDS) for amphetamine users. Addiction, 92(7), 839-845.

Tripodi, S. J. (2009). A comprehensive review: Methodological rigor of studies on residential treatment centers for substance-abusing adolescents. Journal of Evidence-Based Social Work, 6(3), 288-299.
Tsey, K., Whiteside, M., Haswell-Elkins, M., Bainbridge, R., Cadet-James, Y., \& Wilson, A. (2010). Empowerment and indigenous Australian health: A synthesis of findings from family wellbeing formative research. Health \& Social Care in the Community, 18, 169-179. https://doi.org/10.1111/j.1365-2524.2009.00885.x.

Waldram, J. B., Herring, A., \& Young, T. K. (2006). Aboriginal health in Canada. Canada: University of Toronto Press.

Whitesell, M., Bachand, A., Peel, J., \& Brown, M. (2013). Familial, social, and individual factors contributing to risk for adolescent substance use. Journal of Addiction, 2013, 9. https://doi.org/10.1155/2013/579310.

Williams, R. J., \& Chang, S. Y. (2000). A comprehensive and comparative review of adolescent substance abuse treatment outcome. Clinical Psychology: Science and Practice, 7(2), 138-166.

Zetterqvist, M. (2015). The DSM-5 diagnosis of nonsuicidal self-injury disorder: A review of the empirical literature. Child and Adolescent Psychiatry and Mental Health, 9, 31. https://doi.org/10.1186/s13034-015-0062-7.

\section{Publisher's Note}

Springer Nature remains neutral with regard to jurisdictional claims in published maps and institutional affiliations.

Ready to submit your research? Choose BMC and benefit from:

- fast, convenient online submission

- thorough peer review by experienced researchers in your field

- rapid publication on acceptance

- support for research data, including large and complex data types

- gold Open Access which fosters wider collaboration and increased citations

- maximum visibility for your research: over $100 \mathrm{M}$ website views per year

At $\mathrm{BMC}$, research is always in progress.

Learn more biomedcentral.com/submissions 